Article

\title{
Design and Development of a 3D Digital Cadastre Visualization Prototype
}

\author{
Davood Shojaei ${ }^{1,2, *}$, Hamed Olfat ${ }^{1,2}$, Abbas Rajabifard ${ }^{1}$ and Mark Briffa ${ }^{2}$ \\ 1 Centre for SDIs and Land Administration, Department of Infrastructure Engineering, The University of \\ Melbourne, Parkville, VIC 3010, Australia; olfath@unimelb.edu.au (H.O.); abbas.r@unimelb.edu.au (A.R.) \\ 2 Land Use Victoria, Department of Environment, Land, Water and Planning, 2 Lonsdale Street, Melbourne, \\ VIC 3000, Australia; mark.briffa@delwp.vic.gov.au \\ * Correspondence: shojaeid@unimelb.edu.au; Tel.: +61-426-265-751
}

Received: 31 August 2018; Accepted: 22 September 2018; Published: 24 September 2018

\begin{abstract}
The massive property development of high-rises and complex structures above and below the ground surface in cities indicates the lack of land and high demand to use spaces. However, the existing land and property administration systems are mainly two dimensional and not capable of efficiently managing these complex spaces. As ownership rights on plans are recorded in paper or PDF, understanding these rights and making effective decisions and analyses can be difficult without having experience in the art of reading and interpreting plan information. This paper attempts to address these issues by presenting a prototype for visualizing three-dimensional land and property information. The aim of this prototype is to illustrate and communicate the requirements and benefits of a 3D digital cadastre platform. The prototype is a web-based application and includes functionality to display both legal and physical data, interact with 3D models, display administrative data, identify objects and search objects, visualize cross-sections, and undertake measurements in 3D. For this prototype, a multi-story building was selected as a case study and its 3D model was imported into the prototype to display ownership rights. The prototype was then evaluated by various stakeholders and their feedback was considered for future enhancement.
\end{abstract}

Keywords: 3D cadastre; ePlan; land administration; Building Information Modeling; Web Graphics Library; visualization; Land Use Victoria; Australia

\section{Introduction}

The growing population and lack of available land in urban areas has led to intensive property development above and below the ground surface. In these developments, overlapped ownership rights are currently registered in paper/PDF-based plans. This method of registration is not efficient as it does not record ownership boundaries in a digital format and as a result, spatial queries (e.g., finding the car park and storage associated with an apartment) are not supported. Also, this data cannot be readily and efficiently used by other stakeholders such as the Public, land surveyors, developers, real estate agents, strata managers, architects, and city councils.

To move from paper/PDF-based cadastral plans to an efficient and digital approach, an ePlan Working Group (eWG) was formed by the Intergovernmental Committee on Surveying and Mapping (ICSM) in 2003. ICSM is responsible for providing leadership, coordination and standards for surveying, mapping and national datasets in Australia and New Zealand.

eWG's aim was to develop a national model to transfer digital cadastral survey data between the Australian surveying industry and government agencies. In 2009, the ICSM endorsed the national ePlan as an agreed conceptual data model of a cadastral survey that meets the needs of the jurisdictions in Australia [1]. In 2011, an ePlan Protocol was developed to map the components of the ePlan data model 
to LandXML, a specialized XML data file format containing civil engineering and survey measurement data commonly used in the land development and transportation industries (www.landxml.org). ePlan is currently operational in New South Wales and Victoria. The Singapore Land Authority also joined the eWG in 2013 and have adopted the ePlan Protocol for their two dimensional (2D) cadastral surveying modelling and electronic lodgments [2]. New Zealand are also part of the eWG and the cadastral data is transferred via the ePlan LandXML format. New Zealand mandated ePlan in 2007 under Cadastral Survey (Compulsory Lodgment of Digital Cadastral Survey Datasets) Order 2007 [3].

Following the considerable progress of 2D ePlan implementation in Victoria over the past few years and with a major focus of the 'ICSM Cadastre 2034 Strategy' on a three dimensional (3D) digital cadastre for Australia [4], the land registry in Victoria (Land Use Victoria) began to investigate the legal, institutional and technical requirements for developing a 3D digital cadastre for Victoria in 2014. The ICSM 'Cadastre 2034 Strategy' published in 2014 defined a future cadastre being 3D, dynamic and survey accurate [4].

A 3D digital cadastre is expected to facilitate the registration process [5], save time and cost, increase transparency in land and property transactions, and improve land use and management [6]. For example, in a 3D digital cadastre, overlapped spatial units can be validated [7] and geometries can be checked to ensure rights are secured and disputes minimized.

As part of 3D digital cadastre investigation in Victoria, there was a need to facilitate discussions on 3D digital cadastre with various stakeholders. Therefore, a research project was defined and undertaken to investigate possible methods of visualizing 3D spatial objects, the feasibility of implementing a 3D digital cadastre, and to communicate associated benefits with the stakeholders. This paper discusses the results of this research project.

This study has focused on a 3D digital cadastre graphical user interface, necessary functions and the method of visualizing 3D property objects. The results of this study can be expanded to develop a 3D digital cadastre application for showing 3D property units at a city, state or national level.

The paper is structured as follows with five main sections. In Section 2, the previous studies relevant to $3 \mathrm{D}$ digital cadastre and prototypes for showing building subdivision plans are discussed. Section 3 reviews the prototype design and development phases. The evaluation of the prototype usability is addressed in Section 4. Section 5 discusses the results of the evaluation and concludes with a summary and direction for future research.

\section{An Overview of Previous Relevant Studies}

$3 \mathrm{D}$ visualization of cadastral data has been a topic of relevance since $3 \mathrm{D}$ digital cadastre investigations began around the 2000s. Several prototypes have been developed and tested for visualizing 3D Rights, Restrictions and Responsibilities (RRRs). In addition to the progress of this topic, emerging new technologies in computer graphic or improvement in hardware technology have stimulated researchers to design, develop and test various applications.

Several prototypes for presenting 3D digital cadastre concepts have been developed across the world [8-28]. However, none of them have been practically implemented in any jurisdiction. They mainly showcase 3D models similar to a 3D GIS application and have not been developed for 3D cadastral purposes. According to the literature, despite the similar activities in 3D digital cadastre prototype developments, there are several steps for validation that are required before these may be considered as real 3D cadastral applications. Validation of prototypes is an important step towards developing end products and the primary goal is validating the assumptions or methods. There are several approaches for the validation of prototypes. Shojaei [6] used the questionnaire method to validate and assess the usability of prototypes. Elizarova et al. [17] also used a structured questionnaire to evaluate a 3D prototype. Other authors recognized the need for further research in this area $[6,29,30]$.

These prototypes have been designed and implemented using different technologies and include various functionalities. Among them, web-based prototypes were the focus of this review due to their easier accessibilities for most of the users who may not be professional such as the Public. 
Some of the web-based prototypes have been evaluated by users to assess their effectiveness $[17,23,25]$. However, more work is required to understand the way to simply and accurately present ownership rights to suit the need of a large number of cadastral users.

A comprehensive investigation was recently published by looking at the best practices in 3D digital cadastre visualization [31]. Atazadeh et al. [32] used BIMviews and BIMServer to store, publish and visualize IFC files created for a case study in Victoria, Australia. In this study, there was no additional function developed for cadastral purposes on top of the existing functions in BIMviews. Geodata Australia used ArcGIS Pro to capture apartment units in a case study in the Northern Territory and New South Wales in Australia to model strata plans and visualize them in a parcel fabric. Land registry in New South Wales are testing an approach for back capturing strata plans in XML format and visualizing them in ArcGIS Pro (3dgeoinfo2017.com/Files/Harding.pdf). They capture the footprint of apartment units and simply extrude it to an arbitrary height to make 3D units. However, ArcGIS Pro is not a web-based application and general users may have problems accessing this application and even working with it.

In addition to the prototypes, some researchers used 3D PDF to show ownership rights [33-35]. This is a simple approach for showing 3D models. However, the existing functions in Acrobat Reader are very limited. Users cannot easily navigate through the model to see the internal boundaries.

According to the literature review and by looking at different prototypes, it was confirmed that the requirements of 3D digital cadastres have not been finalized and further work is required to identify them through research and development. The developed prototypes show some 3D legal models, but additional work is required to develop and enhance these prototypes according to the feedback from users (industry). This is missing in the literature and this paper attempts to address this by continuously developing and enhancing a prototype to finalize the requirements of the users. In addition, this research mainly focuses on a method to visualize 3D RRRs in a very simple manner, understandable to people with limited expertise in the cadastral domain. The next section explores the development phases.

\section{Design and Development of the 3D Digital Cadastre Prototype}

This section reviews the data, the users and their requirements, and technologies used in designing and developing the prototype. To design and develop the prototype, a case study was defined as the research methodology. Case studies mainly look at real cases and are suitable when types of evidence such as interviews, questionnaires, reports, procedures, and strategic plans are also available [36].

In this case study, a two-story building in Victoria was selected which includes 12 lots and 2 common properties. This building was chosen for its complexity of the structure as well as the availability of the required data.

This section has three main parts including data, users and requirements, and implementation.

\subsection{Data}

3D cadastral data should include both legal and physical data [25]. Physical data includes walls, roofs, ceilings, doors, windows, etc. and legal data are 3D RRRs which are conceptual and abstract. Visualizing both physical and legal information simplifies the interpreting of ownership rights [37].

In Victoria, building subdivision plans (strata plans) are mainly created in PDF format and submitted to land registry. These plans include floor plans and cross-sections, as illustrated in Figure 1. Floor plans and cross-sections assist to define and understand overlapped ownership rights in building subdivision plans [38]. 

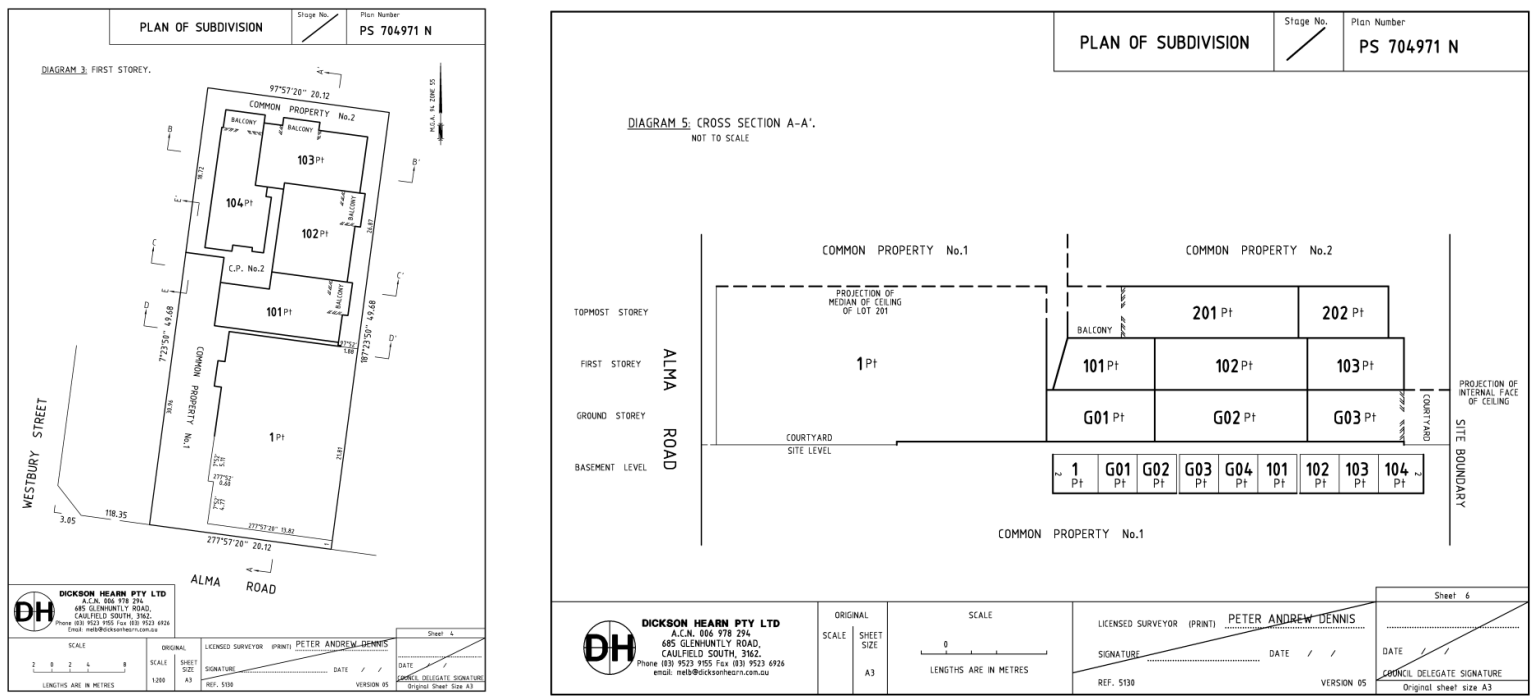

Figure 1. A building subdivision plan in Victoria including floor plans and cross-sections.

However, as shown in Figure 1, building boundaries in subdivision plans in Victoria do not include dimensions (bearing, distance and height) to show the extent of building structures [39]. Due to this, more information is required for modelling subdivision plans in 3D. Therefore, architectural plans were requested and received from the associated surveying firm in DWG format. Autodesk Revit was utilized to create a 3D model based on the architectural plans (Figure 2a). Next, subdivision plans were used to define ownership boundaries in Revit. According to Shojaei et al. [27], legal objects were defined as Room Components within the 3D model. Finally, the model was exported in IFC (Industry Foundation Classes) format (BIM (Building Information Modeling)). As IFC format does not support legal objects, all legal objects (lots and common properties) were defined as IfcSpace (www. buildingsmart-tech.org/ifc/IFC2x3/TC1/html/ifcproductextension/lexical/ifcspace.htm) (Figure 2b). In addition, attribute data for each legal object was added to the 3D model for supporting queries in the prototype. Figure 2 shows the 3D model prepared in this step.

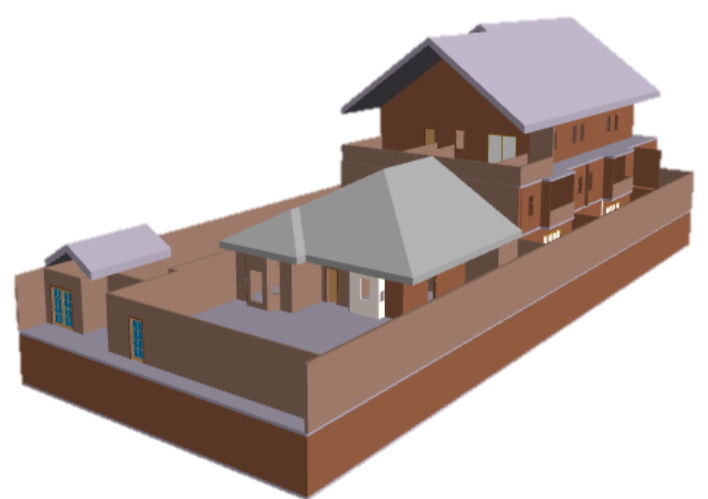

(a)

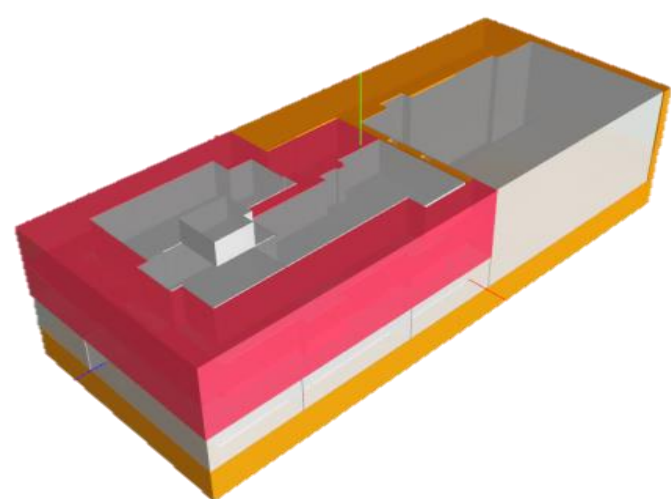

(b)

Figure 2. (a) A snapshot of the prepared 3D physical model. (b) A snapshot of the defined legal model.

\subsection{Users and Requirements}

The end users form the most important parameter for developing an application. Without considering their requirements, applications might not be useful. For this research, a list of users and their 3D cadastral visualization requirements, according to Shojaei [6], were considered. The range of potential users of the 3D digital cadastre in Victoria is very broad and includes the Public, land surveyors, developers, real estate agents, strata managers, architects, and city councils. However, 
the scope of this research has been limited to land surveyors, plan examiners and land administration experts only. Other potential users will be considered in future research. Table 1 lists the considered users' requirements.

Table 1. List of the considered requirements for the prototype development according to Shojaei [6].

\begin{tabular}{cccc}
\hline \multicolumn{4}{c}{ Requirements } \\
\hline Navigation Tools & PDF Visualization & Indoor View & Identify Tool \\
\hline Select Objects & Plan View & Model View & Underground View \\
\hline Platform Independence & Layer and Object Control & $\begin{array}{c}\text { Visualization of Results of } \\
\text { Functions \& Queries }\end{array}$ & Color and Style \\
\hline Transparency & Search & Measurement Tools & Labels \\
\hline Shadow & Web-based & Open-Source & Mobile Friendly \\
\hline Cross-section View & User Friendly & $\begin{array}{c}\text { Physical Model } \\
\text { Visualization }\end{array}$ & Legal Model \\
\end{tabular}

The requirements listed in Table 1 were implemented in the prototype, as described in the next section. The final product would be a simple tool being used by the selected user groups in this research including land surveyors, plan examiners and land administration experts to query, display and interpret ownership rights, restrictions and responsibilities relevant to a property in a 3D digital environment.

To validate the requirements identified in the literature, the prototyping approach [40] was utilized. Prototyping allows practitioners to quickly and easily assess the usability of the proposed requirements.

\subsection{Implementation}

According to the requirements mentioned in Table 1 and among the existing 3D technologies, WebGL was considered due to the following reasons:

- It meets some of the key requirements in Table 1 such as open-source, web-based, mobile friendly, and platform independence.

- WebGL is a popular 3D visualization engine and it grows quickly with the support of many involved users.

- WebGL technology has already been evaluated by Shojaei et al. [27] and it satisfies many 3D cadastral visualization requirements.

- Authors have extensive experience with developing this technology.

Among the existing WebGL libraries, Three.JS (threejs.org) was utilized for developing the prototype. Figure 3 shows the architecture designed for this prototype.

According to Figure 3, this architecture has three sections. The data tier, application tier, and client tier. Data tier includes 3D models, a subdivision plan (a PDF file), an aerial imagery and administrative information including ownership, plan number and owner's corporation schedule. The application tier is responsible for publishing the 3D cadastral data in this prototype using Three.JS libraries, and Apache Tomcat.

The client tier visualizes 3D models derived from the data tier in a Graphical User Interface (GUI). Various technologies were utilized to produce the GUI namely WebGL, HTML 5, JavaScript, Google Map and CSS. The Google Map provides users with the location of the building within the city. In addition, HTML and CSS were utilized to create the GUI with customizable frames, buttons and tabs to build a suitable application interface. To render 3D models, WebGL technology was used to visualize physical and legal objects, and aerial imagery, with the essential functions to explore the 3D model. Figure 4 shows snapshots of the prototype. 


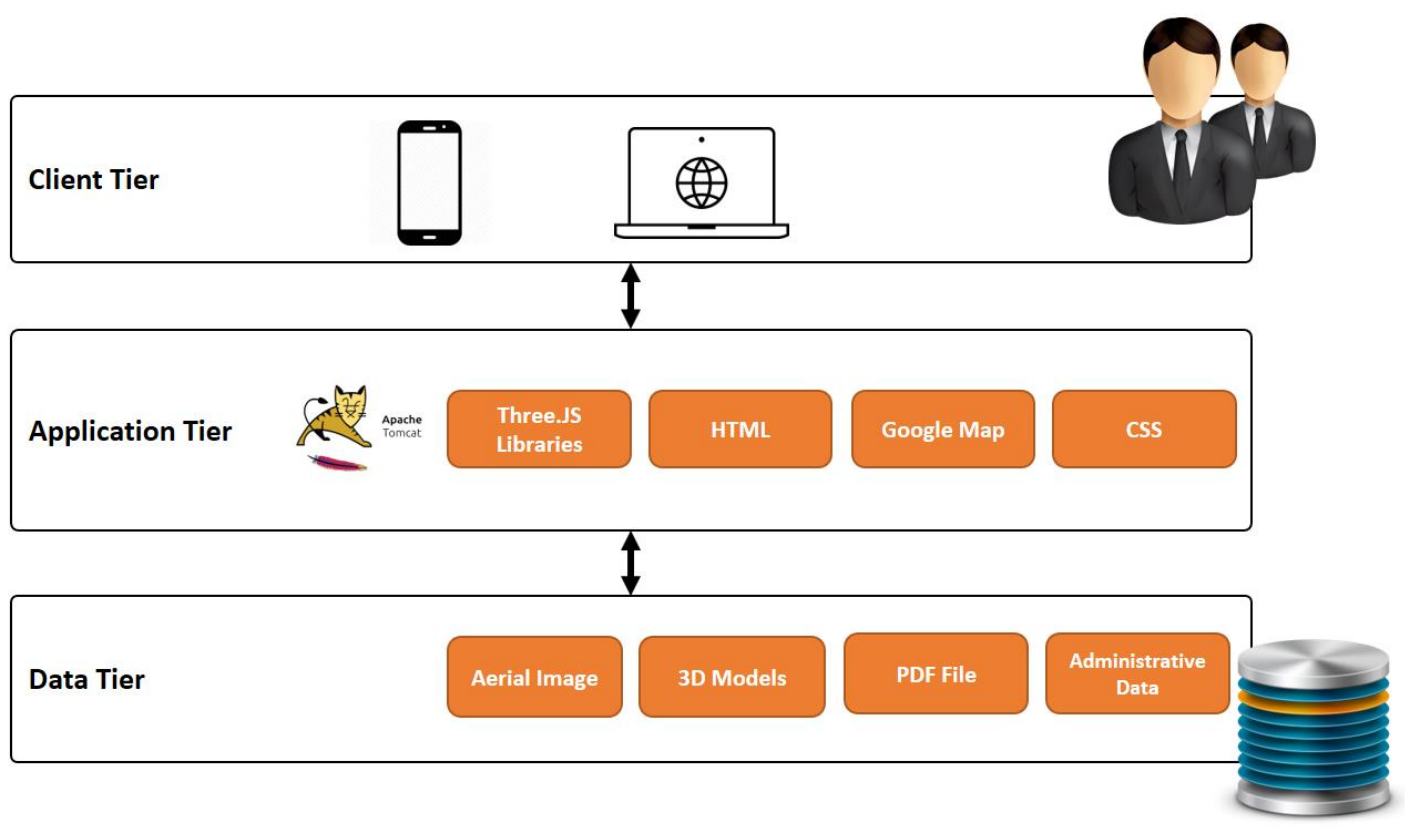

Figure 3. The proposed architecture for the development of the prototype.

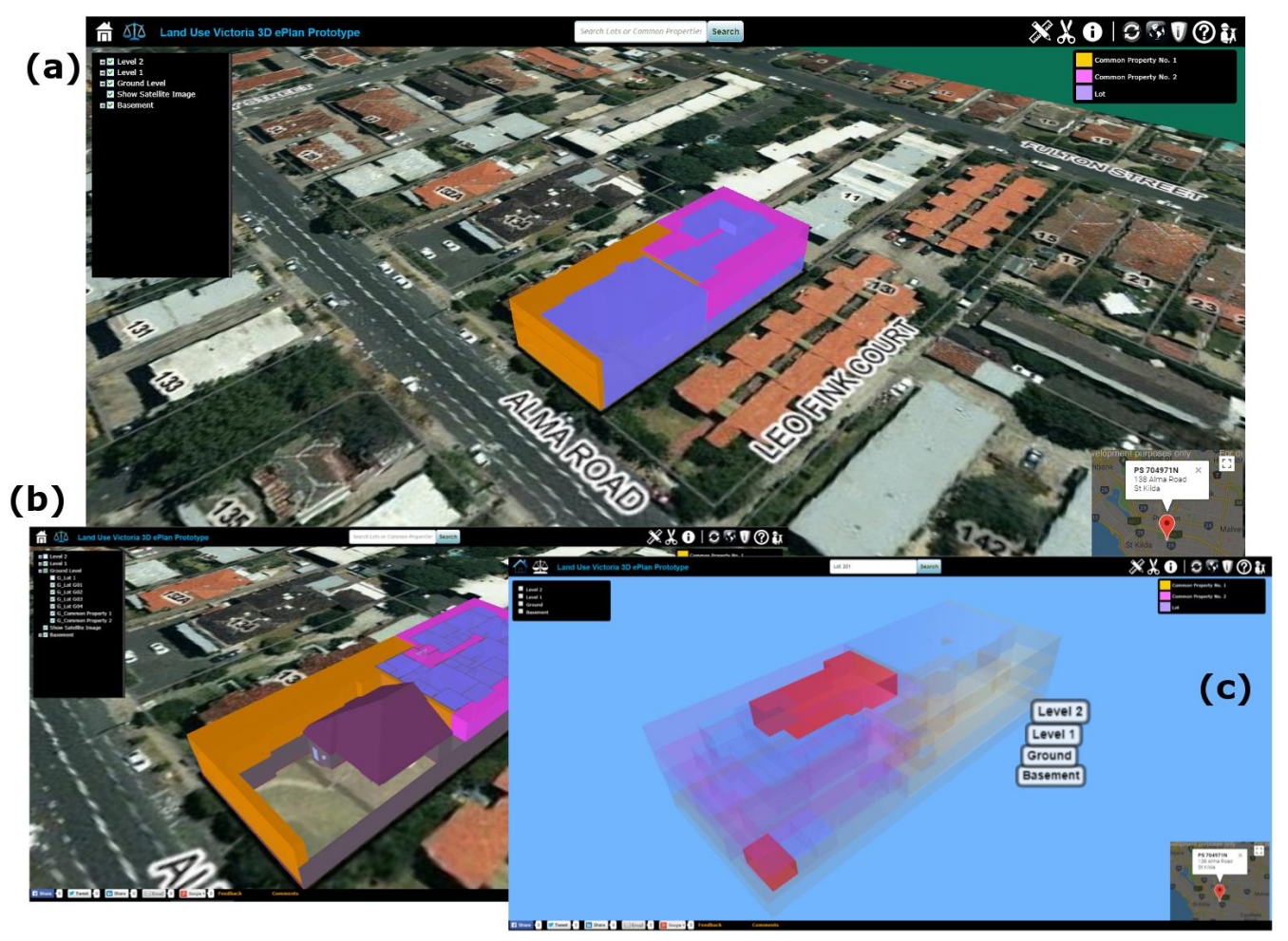

Figure 4. (a) A snapshot of the prototype (www.spear.land.vic.gov.au/spear/pages/eplan/3d-digitalcadastre/3dprototype/prototype.html). (b) A combined visualization of the building (physical and legal view). (c) Search of a lot within the building displaying an apartment unit and its car park.

The features of the prototype are described below in detail followed by a review of development challenges. 


\subsubsection{Features}

The following features were developed in the prototype according to the requirements.

- Identify Tool

Identify tool retrieves and displays information included in each object in the scene. The identify tool is not an available tool in the Three.JS library. Therefore, this tool was developed using the ray casting technique to detect objects in 3D space. By a mouse click on the objects in the scene, the 2D mouse position is translated to 3D by adding a depth (e.g., 1 or 0.5 ) to the 2D mouse coordinate on the screen. Then a ray is casted from this position to the camera location. The intersections of this ray with the 3D model are stored in an array. The nearest element to the camera in this array is the object in the 3D model clicked by the mouse. This object is highlighted, and its attributes are visualized.

\section{- Distance Measurement Tool}

The distance measurement tool was developed to measure distances in the 3D model. By clicking on the 3D model, the ray casting technique is used to calculate the 3D coordinate of the mouse. By having two sets of coordinates, a 3D distance is calculated, and a line is drawn to show where the measured distance is.

\section{- Cross-section Tool}

Cross-section is a useful tool to display the interior geometry of a structure. Two methods were explored for implementing this tool. In the first method, the two clipping planes (near and far) for the camera object in Three.JS can be used to cut through the objects. Any object between these two clipping planes will be rendered and any object which intersects with these planes will be cut. Therefore, by changing the distance of the near clipping plane from the camera, different cuts through the objects can be viewed. This approach is not efficient because it is limited to the camera location. By changing the camera location in the scene, the section view is changed.

The second approach lets defining clipping plane for an object in any direction and allows the camera to move around the objects to provide a better view to the remaining objects in the scene. Clipping planes support was added in the release version 76 of Three.JS library.

Therefore, the second approach was considered for development in the prototype as it gives more flexibility to the user to define clipping planes.

\section{- Search and Find Tool}

One of the important requirements for this prototype is the ability to search and find objects. In this tool, objects are found and highlighted according to their attributes. For example, the name of apartments can be searched (See Figure 4c). Thus, after entering an attribute of the objects in the search box, objects including this attribute are detected and highlighted. Once the query is removed, the original color is restored.

\section{- Object Control}

There are two sets of lists on the left side of the GUI, which provide users with control over object visibility. One list relates to physical objects, the other to legal objects. This allows any combination of physical and legal objects to be viewed (See Figure $4 \mathrm{~b}$ ). In addition to objects, an aerial imagery has also been added to the scene which can be visualized or hidden.

- Representing Plan Information

The prototype shows plan information (the subdivision plan) in PDF. Users such as land surveyors can refer to it for more detailed information as a legal document.

- Touch and Tap Events

Touch and tap events were added to the prototype to support mobile devices (e.g., tablets or smartphones). Touch and tap events are interpreted in the same way as click events. 


\subsubsection{Technical Development Considerations}

During the development phase, various technical issues were resolved which are described below.

- Camera Control

The camera object was configured to be limited to some specific rotations to increase the usability of the prototype and to have better control over the objects in the prototype. This customization limits the camera to display the 3D models upside down.

\section{- Smooth Navigation}

Zoom and pan should be efficiently designed in the prototype for better navigation. For example, the movement must be smooth, and the amount of movement should be related to the distance of the camera to the object of interest. It means finer movements when the camera is closer to the object. Pan tool should follow the same technique. The pan speed should be less when the camera is closer to the object and vice versa. Accordingly, the zoom and pan speeds were configured in the camera object to dynamically change to have better smoothness in navigation.

\section{- Support for Popular Internet Browsers}

In order to support popular Internet browsers in the prototype, the source code was modified to work on different browsers. Now the prototype is supported in Chrome, Firefox, Internet Explorer, and Safari.

To test the usability of the prototype, an evaluation approach was utilized which is discussed in the next section.

\section{Usability Evaluation}

Evaluating the prototype is an important aspect of this research. In this study, a quantitative method was chosen to evaluate the usability of the prototype, which is described below.

\subsection{Choosing the Prototype Testers}

The snowball sampling approach was used to find specialists to evaluate the prototype at Land Use Victoria. 28 land administration specialists including 11 land surveyors, 6 plan examiners, and 11 land administration experts who are intimately involved in cadastral process agreed to help in this assessment for evaluating this prototype (www.surveymonkey.com/ $\mathrm{mp} /$ sample-size-calculator/?ut_ source=help_center). They were invited into several evaluation meetings to see the prototype and to fill in a survey at the end. All participants were from Victoria, Australia, as the case study is in this state and the prototype has been implemented based on legislation and regulations in Victoria.

\subsection{Usability Evaluation of the Prototype}

Among various methods for usability evaluation, SUS (System Usability Scale) was considered in this study as an evaluation framework. The method has 10 questions (see Table 2) to help better understanding the usability of the prototype.

The SUS method has several advantages among other assessment methods according to Bangor et al. [41]:

- The questions are technology agnostic, which make the method flexible enough to evaluate a wide range of applications.

- The method is simple and fast for participants and administrators.

- The method provides a score which is simple to understand to assess usability.

- The survey is non-proprietary, making it a cost-effective tool as well.

The above advantages justify the SUS method as a suitable assessment method in this research for evaluation of the prototype usability. 
An online questionnaire including 10 phrases was designed and prepared to share with the participants in the sessions. It was asked to imagine this prototype is available for all properties in Victoria and not only one building. The responses were recoded according to the Likert Scale ranging from strongly disagree (0) to strongly agree (4). According to the responses, Table 2 lists the percentage of all participants for each phrase.

Table 2. The list of phrases according to SUS method.

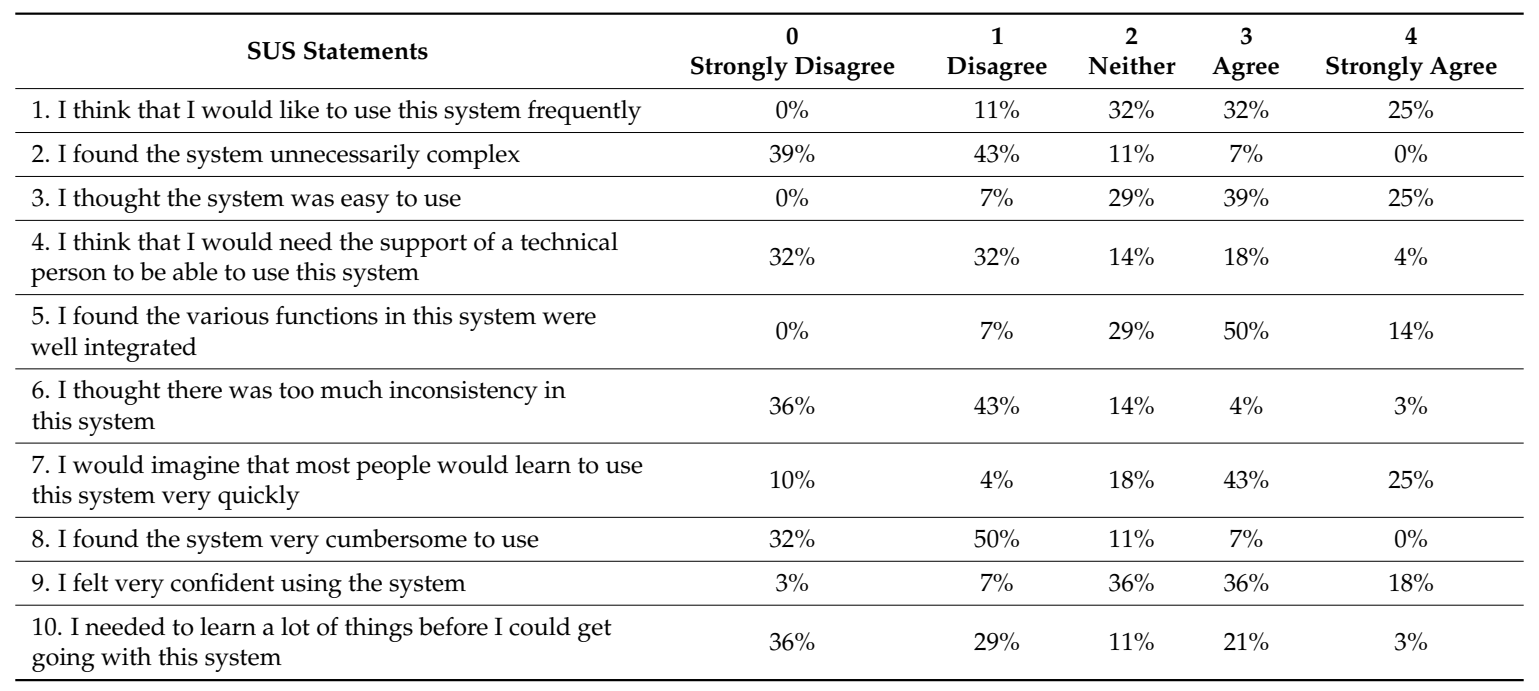

According to Table 2, the responses to each statement show the feedback from participants which can be separately analyzed. For example, responses to the odd statements (1,3,5,7 and 9) show participants relatively agree with the statements. In addition, the even statements have strongly disagree and disagree in most of the cases as the highest percentages. Therefore, it can be expected the overall usability score should be in a good situation.

In order to calculate the overall usability score, the score from each phrase is calculated. Each phrase will range from 0 to 4 . For items 1, 3, 5, 7 and 9 the score is the scale position minus 1. For items 2, 4, 6, 8 and 10, the contribution is 5 minus the scale position. Then, the sum of the scores is multiplied by 2.5. Finally, the SUS final score is calculated by the average of the overall sum. SUS scores have a range of 0 to 100 .

The overall SUS score was calculated as 70.44 out of 100 . According to the rule-of-thumb standard, the so-called 'university grade analog', discussed by Bangor et al. [41] and illustrated in Figure 5, the SUS score is between 'OK' and 'GOOD' ratings, among 'worst imaginable', 'poor', 'ok', 'good', 'excellent', and 'best imaginable' ratings.

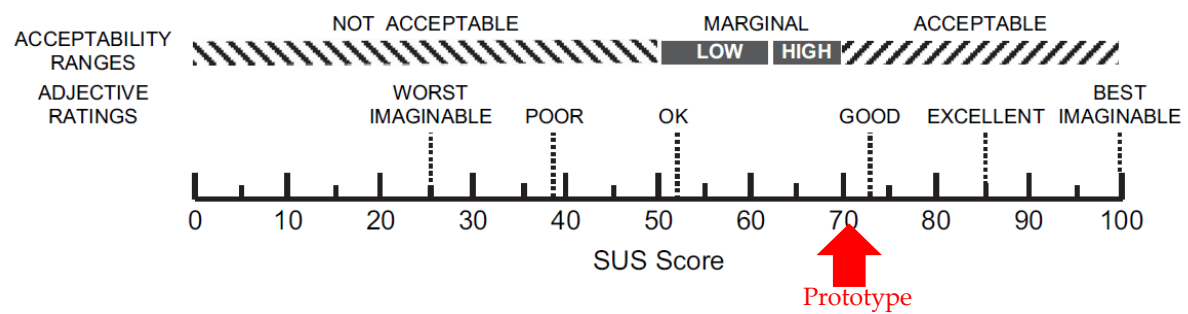

Figure 5. The rating and acceptability of the VET according to the SUS rule-of-thumb standard (adopted from Bangor et al. [41]).

Based on this method, the prototype is in the 'acceptable' range among 'not acceptable', 'low marginal', 'high marginal', and 'acceptable' ranges. This means that the prototype is at least acceptable because it has an SUS score above 70 but can be improved in terms of usability. The details of the evaluation results and participants' feedback are discussed in the next section. 


\section{Discussion and Conclusions}

Following the focus of the ICSM Cadastre 2034 Strategy on a 3D digital cadastre for Australia, a research project was defined at Land Use Victoria to develop a prototype to define 3D digital cadastre concepts and requirements and communicate them with relevant stakeholders.

To achieve the research aim, various technologies were reviewed and investigated. WebGL was chosen as the most suitable technology. As part of this study, Autodesk Revit was also utilized for creating the 3D model and defining ownership rights in the 3D model in IFC format. After development of the prototype, the usability of the prototypes was evaluated.

Overall, the evaluation results showed that the prototype was an acceptable product in terms of usability and for representing the concept of a 3D digital cadastre to the users involved in this study. The suggestions received from the evaluation participants are also classified in Table 3 for further discussion and potential consideration. Table 3 includes the suggestions and research team's responses/actions.

Table 3. The research team's responses/actions to the participants' feedback.

\begin{tabular}{|c|c|c|}
\hline Category & Participants' Feedback & The Team's Responses/Actions \\
\hline \multirow{7}{*}{ Data } & $\begin{array}{l}\text { "The prototype should be able to show } \\
\text { boundary information as the primary } \\
\text { function. All building features are } \\
\text { secondary to title boundary". } \\
\text { "Better way of showing the location of } \\
\text { building boundaries in the prototype can } \\
\text { facilitate interpreting the boundary } \\
\text { locations (e.g., interior face)". }\end{array}$ & $\begin{array}{l}\text { This shows the significance of boundary delimitation in the prototype } \\
\text { which can be improved. For example, the identify tool can be } \\
\text { customized in a way to show the type of boundary as there are four } \\
\text { types (Median, Exterior, Interior, Other) in Victoria. }\end{array}$ \\
\hline & $\begin{array}{l}\text { "Architectural design might not be } \\
\text { compatible with the survey plan (as-built)". }\end{array}$ & $\begin{array}{l}\text { A new measurement may be required at the time of defining legal } \\
\text { objects to assure there is no discrepancy between the model } \\
\text { and as-built. }\end{array}$ \\
\hline & $\begin{array}{l}\text { "Common property needs to be shown } \\
\text { between the lots (wall, ceiling, floors) } \\
\text { if applicable". }\end{array}$ & $\begin{array}{l}\text { One of the current challenges in the prototype is visualizing the } \\
\text { common property spaces which reside in the walls, ceiling and floors } \\
\text { between legal objects. These may contain infrastructure of buildings } \\
\text { such as pipes, cables, ducts, etc. As Figure } 6 \text { shows, the highlighted } \\
\text { wall belongs to common property number one and is not shown in the } \\
\text { prototype as a common property space. Visualizing such objects in the } \\
\text { 3D model will result in a complex visualization. That is why they are } \\
\text { not visualized in the prototype and similar to the subdivision plan, they } \\
\text { are defined as the below notation in the prototype: }\end{array}$ \\
\hline & $\begin{array}{l}\text { "Common property must be linked to lots } \\
\text { to show the connections". }\end{array}$ & This will be considered as a future enhancement. \\
\hline & $\begin{array}{l}\text { "The prototype must be able to show } \\
\text { everything on the plan diagram, or it } \\
\text { cannot replace the plan as title diagram". }\end{array}$ & The prototype will be compared with the plan to include all the details. \\
\hline & $\begin{array}{l}\text { "Remove walls that not showing building } \\
\text { boundaries (internal walls)". }\end{array}$ & This needs to be investigated further. \\
\hline & $\begin{array}{l}\text { "Add all physical components (e.g., pipes, } \\
\text { and cables) to help with Owners } \\
\text { Corporation disputes resolution process". }\end{array}$ & $\begin{array}{l}\text { Adding them to the 3D model can help in a case of dispute. However, } \\
\text { in this model, there was no access to the utility network objects. }\end{array}$ \\
\hline \multirow{5}{*}{ System } & $\begin{array}{l}\text { "Parcel areas, Owners Corporation } \\
\text { membership, street address, and title } \\
\text { information (Volume/Folio) should be } \\
\text { shown when selecting lots" }\end{array}$ & This is considered as a future enhancement. \\
\hline & $\begin{array}{l}\text { "Snap is required in measurement tool. } \\
\text { Also, user should be able to move the end } \\
\text { points after placing them in the prototype } \\
\text { for measurements". }\end{array}$ & This is considered as a future enhancement. \\
\hline & $\begin{array}{l}\text { "Need to show bearings and distances to } \\
\text { fully define parcels". }\end{array}$ & $\begin{array}{l}\text { The model needs to be updated to show the boundary location by } \\
\text { bearing and distance. }\end{array}$ \\
\hline & $\begin{array}{l}\text { "When the camera goes underground, } \\
\text { the base map should be shown as } \\
\text { a transparent layer". }\end{array}$ & This is considered as a future enhancement. \\
\hline & "Showing height and depth limitations". & $\begin{array}{l}\text { This needs further investigation as it is difficult to show unlimited } \\
\text { ownership rights. }\end{array}$ \\
\hline
\end{tabular}




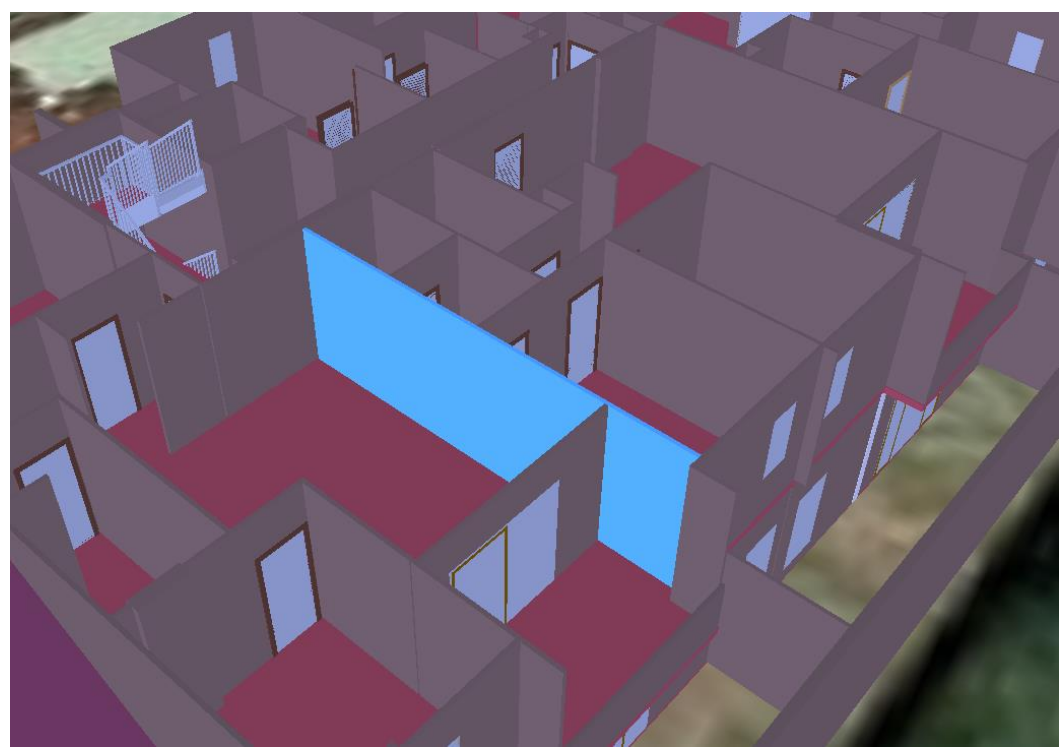

Figure 6. The highlighted wall is part of the Common Property No. 1 in this 3D model and due to the complexity in the 3D model, it is not shown as a legal object.

The Victorian 3D digital cadastre prototype will be enhanced using the feedback received from the evaluation study participants, reviewed in Table 3. The research team's main areas of focus include improving the 3D visualization of common property and lot boundaries, testing the prototype with some additional datasets, developing boundary identification tool, investigating the 3D data capturing methods, researching methods to store 3D models in a database.

Author Contributions: D.S., H.O. and M.B. contributed to the development of the prototype and conducted the interviews with participants and analyzed the outcomes. A.R. contributed to the development of the Victorian 3D digital cadastre initiative and provided feedback throughout the project.

Funding: This research received no external funding.

Acknowledgments: The authors would like to thank Land Use Victoria staff and the Centre for Spatial Data Infrastructures and Land Administration (csdila.unimelb.edu.au) at the University of Melbourne for sharing their thoughts and contributing to this paper. This paper is based on the view of the authors and may not represent the view of Land Use Victoria.

Conflicts of Interest: The authors declare no conflict of interest.

\section{References}

1. Aien, A.; Kalantari, M.; Rajabifard, A.; Williamson, I.; Shojaei, D. Developing and Testing a 3D Cadastral Data Model: A Case Study in Australia. XXII ISPRS Congress; ISPRS Annals of the Photogrammetry: Melbourne, Australia, 2012.

2. Soon, K.H. A Conceptual Framework of Representing Semantics for 3D Cadastre in Singapore. In Proceedings of the 3rd International Workshop on 3D Cadastres: Developments and Practices, Shenzhen, China, 25-26 October 2012.

3. LINZ Cadastral Survey (Compulsory Lodgment of Digital Cadastral Survey Datasets) Order 2007. Available online: http:/ / www.legislation.govt.nz/regulation/public/2007/0215/latest/DLM444505.html?search= ts_regulation\%40deemedreg_cadastral_resel_25_a\&p=1 (accessed on 16 January 2018).

4. ICSM. Cadastre 2034 Strategy Powering Land and Real Property. March 2015. Available online: https: / /www.icsm.gov.au/sites/default/ files/Cadastre2034.pdf (accessed on 23 August 2018).

5. Aien, A.; Rajabifard, A.; Kalantari, M.; Shojaei, D. Integrating Legal and Physical Dimensions of Urban Environments. Int. J. Geo-Inf. 2015, 4, 1442-1479. [CrossRef]

6. Shojaei, D. 3D Cadastral Visualisation: Understanding Users' Requirements. Ph.D. Thesis, The University of Melbourne, Melbourne, Australia, 2014. 
7. Shojaei, D.; Olfat, H.; Quinones Faundez, S.; Kalantari, M.; Rajabifard, A.; Briffa, M. Geometrical data validation in 3D digital cadaster-A case study for Victoria, Australia. Land Use Policy J. 2017, 68, 638-648. [CrossRef]

8. Coors, V. 3D-GIS in Networking Environments. Comput. Environ. Urban Syst. 2003, 27, 345-357. [CrossRef]

9. Stoter, J.; Salzmann, M. Towards a 3D Cadastre: Where Do Cadastral Needs and Technical Possibilities Meet? Comput. Environ. Urban Syst. 2003, 27, 395-410. [CrossRef]

10. Stoter, J.E. 3D Cadastre. Ph.D. Thesis, TU Delft, Delft, The Netherlands, 2004.

11. Lemmen, C.; Van Oosterom, P.; Thompson, R.; Hespanha, J.; Uitermark, H. The Modelling of Spatial Units (Parcels) in the Land Administration Domain Model (LADM). In Proceedings of the FIG Congress 2010, Sydney, Australia, 11-16 April 2010.

12. Dimovski, V.; Bundaleska-Pecalevska, M.; Cubrinoski, A.; Lazoroska, T. WEB Portal for Dissemination of Spatial Data and Services for the Needs of the Agency for Real Estate Cadastre of the Republic of Macedonia (AREC). In Proceedings of the 2nd International Workshop on 3D Cadastres, Delft, The Netherlands, 16-18 November 2011.

13. Aditya, T.; Iswanto, F.; Wirawan, A.; Laksono, D.P. 3D Cadastre Web Map: Prospects and Developments. In Proceedings of the 2nd International Workshop on 3D Cadastres, Delft, The Netherlands, 16-18 November 2011; Fendel, E., van Oosterom, P., Ploeger, H., Stoter, J., Streilein, A., Tijssen, T., Eds.;

14. Guo, R.; Li, L.; He, B.; Luo, P.; Ying, S.; Zhao, Z.; Jiang, R. 3D Cadastre in China-A Case Study in Shenzhen City. In Proceedings of the 2nd International Workshop on 3D Cadastres, Delft, The Netherlands, 16-18 November 2011.

15. Chiang, H.-C. Data Modelling and Application of 3D Cadastral in Taiwan. In Proceedings of the 3rd International Workshop on 3D Cadastres: Developments and Practices, Shenzhen, China, 25-26 October 2012.

16. Vandysheva, N.; Sapelnikov, S.; Van Oosterom, P.; De Vries, M.; Spiering, B.; Wouters, R.; Hogeveen, A.; Penkov, V. The 3D Cadastre Prototype and Pilot in the Russian Federation. In Proceedings of the FIG Working Week, Rome, Italy, 6-10 May 2012.

17. Elizarova, G.; Sapelnikov, S.; Vandysheva, N.; Pakhomov, S. Russian Federation. In Russian-Dutch Project "3D Cadastre Modelling in Russia". In Proceedings of the 3rd International Workshop on 3D Cadastres: Developments and Practices, Shenzhen, China, 25-26 October 2012.

18. Shojaei, D.; Rajabifard, A.; Kalantari, M.; Bishop, I.D.; Aien, A. Development of a 3D ePlan/LandXML Visualisation System in Australia. In Proceedings of the 3rd International Workshop on 3D Cadastres: Developments and Practices, Shenzhen, China, 25-26 October 2012.

19. Ying, S.; Guo, R.; Li, L.; He, B. Application of 3D GIS to 3D Cadastre in Urban Environment. In Proceedings of the 3rd International Workshop on 3D Cadastres: Developments and Practices, Shenzhen, China, 25-26 October 2012.

20. Jamil, H.; Mohd Yusoff, M.Y.; Abdul Halim, N.Z. Discovering Possibilities of Implementing Multipurpose Cadastre in Malaysia. In Proceedings of the FIG Working Week 2013, Abuja, Nigeria, 6-10 May 2013.

21. Ammar, R.K.; Neeraj, D. SLRB Bahrain-3D Property Registration System. In Proceedings of the 5th Land Administration Domain Model Workshop, Kuala Lumpur, Malaysia, 24-25 September 2013.

22. Zulkifli, N.A.; Abdul Rahman, A.; Van Oosterom, P. Developing 2D and 3D Cadastral Registration System based on LADM: Illustrated with Malaysian Cases. In Proceedings of the 5th Land Administration Domain Model Workshop, Kuala Lumpur, Malaysia, 24-25 September 2013.

23. Budisusanto, Y.; Aditya, T.; Muryamto, R. LADM Implementation Prototype for 3D Cadastre Information System of Multi-Level Apartment in Indonesia. In Proceedings of the 5th Land Administration Domain Model Workshop, Kuala Lumpur, Malaysia, 24-25 September 2013.

24. Guo, R.; Li, L.; Ying, S.; Luo, P.; He, B.; Jiang, R. Developing a 3D cadastre for the administration of urban land use: A case study of Shenzhen, China. Comput. Environ. Urban Syst. 2013, 40, 46-55. [CrossRef]

25. Shojaei, D.; Kalantari, M.; Bishop, I.D.; Rajabifard, A.; Aien, A. Visualization requirements for 3D cadastral systems. Comput. Environ. Urban Syst. 2013, 41, 39-54. [CrossRef]

26. Guo, R.; Luo, F.; Zhao, Z.; He, B.; Li, L.; Luo, P.; Ying, S. The Applications and Practices of 3D Cadastre in Shenzhen. In Proceedings of the 4th International Workshop on 3D Cadastres, Dubai, United Arab Emirates, 9-11 November 2014.

27. Shojaei, D.; Rajabifard, A.; Kalantari, M.; Bishop, I.D.; Aien, A. Design and Development of a Web-based 3D Cadastral Visualisation Prototype. Int. J. Digit. Earth 2014, 8, 538-557. [CrossRef] 
28. Ribeiro, A.; Duarte de Almeida, J.-P.; Ellul, C. Exploring CityEngine as a Visualization Tool for 3D Cadastre. In Proceedings of the 4th International Workshop on 3D Cadastres, Dubai, United Arab Emirates, 9-11 November 2014.

29. Pouliot, J. Visualization, Distribution and Delivery of 3D Parcels. In Proceedings of the 2nd International Workshop on 3D Cadastres, Delft, The Netherlands, 16-18 November 2011.

30. Van Oosterom, P. Summary of the Third International FIG Workshop on 3D Cadastres-Developments and Practices. In Proceedings of the Third International FIG Workshop on 3D Cadastres-Developments and Practices, Shenzhen, China, 25-26 October 2012.

31. Pouliot, J.; Ellul, C.; Hubert, F.; Wang, C.; Rajabifard, A.; Kalantari, M.; Shojaei, D.; Atazadeh, B.; Van Oosterom, P.; De Vries, M.; et al. Visualization and New Opportunities. In Best Practices 3D Cadastres: Extended Version; FIG Publication: Copenhagen, Denmark, 2018; Chapter 5; pp. 183-230.

32. Atazadeh, B.; Kalantari, M.; Rajabifard, A.; Ho, S.; Ngo, T. Building information modelling for high-rise land administration. J. Trans. GIS 2016, 21, 91-113. [CrossRef]

33. Aien, A.; Rajabifard, A.; Kalantari, M.; Williamson, I.P.; Shojaei, D. 3D Cadastre in Victoria, Converting Building plans of Subdivision to LandXML. GIM Int. 2011, 25, 16-21.

34. Stoter, J.; Ploeger, H.; Roes, R.; van der Riet, E.; Biljecki, F.; Ledoux, H.; Kok, D.; Kim, S. Registration of Multi-Level Property Rights in 3D in The Netherlands: Two Cases and Next Steps in Further Implementation. Int. J. Geo-Inf. 2017, 6, 158. [CrossRef]

35. Gulliver, T.; Haanen, A.; Goodin, M. A 3D Digital Cadastre for New Zealand and the International Opportunity. Int. J. Geo-Inf. 2017, 6, 375. [CrossRef]

36. Yin, R.K. Case Study Research: Design and Methods; SAGE Publications: Thousand Oaks, CA, USA, 1994.

37. Aien, A.; Kalantari, M.; Rajabifard, A.; Williamson, I.; Wallace, J. Towards Integration of 3D Legal and Physical Objects in Cadastral Data Models. Land Use Policy 2013, 35, 140-154. [CrossRef]

38. Aien, A.; Rajabifard, A.; Kalantari, M.; Williamson, I.; Shojaei, M. Development of XML Schemas for Implementation of a 3D Cadastral Data Model. In Proceedings of the 4th International Workshop on 3D Cadastres, Dubai, UAE, 9-11 November 2014.

39. Victorian Consolidated Regulations (2011). Subdivision (Registrar's Requirements) Regulations 2011. Retrieved 24 September 2015. Available online: http://www5.austlii.edu.au/au/legis/vic/consol_reg/ srr2011538/ (accessed on 24 September 2018).

40. Kotonya, G.; Sommerville, I. Requirements Engineering: Processes and Techniques; John Wiley \& Sons Ltd.: New York, NY, USA, 1998.

41. Bangor, A.; Kortum, P.T.; Miller, J.T. An Empirical Evaluation of the System Usability Scale. International. J. Hum.-Comput. Interact. 2008, 24, 574-594. [CrossRef] 